\title{
Social Integration and Attitudes towards the Integration of Immigrants in Relation to Witnessing Domestic Aggression
}

\author{
Ingrida Grigaitytè \\ ingrida.grigaityte@abo.fi \\ Developmental Psychology Department at Åbo Akademi University in Vasa, \\ Finland \\ Karin Österman \\ karin.osterman@abo.fi \\ Developmental Psychology Department at Åbo Akademi University in Vasa, \\ Finland \\ Kaj Björkqvist \\ kaj.bjorkqvist@abo.fi \\ Developmental Psychology Department at Åbo Akademi University in Vasa, \\ Finland
}

\begin{abstract}
The association between witnessing domestic aggression and respondents' level of social integration and their proactive attitudes towards the integration of immigrants was assessed with a questionnaire in a sample of the Swedish-speaking minority in Ostrobothnia, Western Finland ( $n=298 ; 208$ females and 90 males). The age span was between 16 and 90 years with a mean age of 31.6 years $(S D=13.5)$. Respondents scoring higher than average on witnessing domestic aggression scored lower than others on the following scales measuring social integration: Access to Social Benefits, Positive Social Relations, and Trust in the Finnish Judiciary System. They also scored lower than others on the following scales measuring proactive attitudes towards the integration of immigrants: (the need for making) Cultural Efforts, Structural Efforts, and Openness to Diversity. They also tended to have a lower level of education than other respondents. The implications of the findings are discussed.
\end{abstract}

Keywords: Social integration, attitudes towards immigrants' integration, witnessing domestic aggression

Received 23 April 202I/Accepted I October 202 I CAuthor all rights reserved

\section{Introduction}

Over the past few decades, social scientists have provided evidence showing that there is a well-established connection between social relationships and health (Umberson \& Montez, 2010). Research has demonstrated that structural aspects of social relationships and their 
processes affect health outcomes in populations in terms of their physical, mental, and emotional health, both immediately and persistently (Cohen, 2004; Uchino, Holt-Lunstad, Uno, Campo, \& Reblin, 2007).

Social integration suggests an overall level of participation in formal and informal social relationships, and their extent and perceived quality either supports or undermines overall health behavior (Umberson \& Montez, 2010). Proactive attitudes towards the integration of immigrants, including cultural efforts, structural efforts, and openness to diversity reflect society's willpower for inclusion, which further supports social health behavior (World Health Organization, 2010). Domestic aggression is a substantial social, physical, mental, and emotional health concern. Thus, the main factors associated with domestic aggression are connected to social integration and socio-demographics (Soler, Vinayak, \& Quadagno, 2000).

To our knowledge, this is the first study that explores a link between social integration, proactive attitudes towards the integration of immigrants, and witnessing domestic aggression. Thus, it is the first study investigating these associations in the context of the Swedish-speaking population of Western Finland (the Finland-Swedes). It is expected that an association will be found, although it would not represent a cause-effect relationship; rather, it would be an indicator of that a certain subgroup of individuals shares similar characteristics. To these characteristics belong living in a family where interpersonal aggression is more common, being poorly integrated with the surrounding society, and having more negative attitudes towards immigrants. This subgroup would also be likely to have a somewhat lower level of education. The study is a part of a larger project investigating social integration and attitudes towards the integration of immigrants in a sample from the Swedish-speaking population living in Western Finland.

Social Integration of The Swedish-speaking Population in Western Finland Ager and Strang (2008) have proposed a conceptual framework that evaluates social integration in terms of peoples' relationship to such realms as (I) rights and citizenship, (2) language and cultural knowledge, (3) safety and stability, (4) social bridges, (5) bonds and links, (6) employment, (7) housing, (8) education, and (10) health. In addition, Esser (1980) includes 
emotional processes concerning identity formation and belonging during the integration. Further, Strang and Ager (2010) explain that social integration must be approached as a reciprocal and continuing process. The success of social integration is linked to the resourcefulness of an immigrant and openness of the hosting society. Also, it relates to the conditions and the actual participation of a newcomer in various aspects of community life, and it narrates the newcomer's intrinsic sense of belonging and being a member of a larger society (Strang \& Ager, 2010). Thus, the success of integration depends on the degree, quality, and occurrence of official and casual social interactions. Formal relationships are defined, generated, and developed in terms of structure and system, e.g., an individual's engagement with religious or voluntary institutions. In contrast, informal relationships refer to ungoverned and voluntary relationships among people, such as being married or living together with an extended family (Brissette, Cohen, \& Seeman, 2000).

The Swedish-speaking population of Finland is considered as a comparatively well-adjusted and well-accepted minority. The existence of Swedish speakers in the country has a long history starting from around 1200 when Finland still belonged to Sweden (Engman, 1995; Törnblom, 1993). Today, the Swedish language and culture are protected by the national constitution and other relevant legislation stating that the Finnish and Swedish languages are both official and have an equal status. The Swedish-speaking minority has its own day-cares, schools, higher-level education institutions, media, churches, and political party; the main language of communication in these is Swedish. Finnish citizens have the right to choose whether they wish to communicate with authorities, such as the law enforcement or court, in Finnish or Swedish. As another example, when doing their compulsory military service, soldiers have the right to be placed in units where they are receiving training in the language of their choice (Saarela, 2020; Tarkiainen, 2008).

Depending on the composition of the population and the language in which residents are registered, Finnish municipalities may be bilingual or monolingual. Most Swedish-speakers live in the coastal areas of Nyland, Åboland, Åland, and Ostrobothnia, which is located on the west coast. To this day, Western Finland emerges as a county where the Swedish language and culture prosper in comparison with other areas of Swedish-speaking Finland. The 
Swedish-speaking minority within the region fractionally comprises half of the population, meanwhile the total number of the Swedish-speakers in the country reach only $5,9 \%$ of the total population (Official Statistics Finland, 202I).

\section{Proactive Attitudes towards Integration}

Proactive attitudes towards integration include potential efforts and responsibilities carried out by both individual people and stakeholders at governmental and county levels. Cultural efforts towards integration are connected to the willingness to accommodate newcomers by the hosting population. This involves acceptance and promotion of minority's culture and beliefs (Phelps, Eilertsen, Türken, \& Ommundsen, 20II). Thus, the realm of cultural integration is characterized by balanced behavioral adaptation that is influenced by pay-offs and changes in preferences shaped by coordination, socialization, and self-persuasion by all participants. This type of behavior alters existing cultural groups to form beneficial contacts among the community members (Kuran \& Sandholm, 2008).

Structural efforts refer to required changes taking place within the institutions and their structures. This may include changes occurring in such spheres such as law, public service, and welfare distribution. (Phelps, Eilertsen, Türken, \& Ommundsen, 20II). Appropriate actions should be taken to reevaluate established social conventions to build a society based on equal rights and responsibilities for all the citizens and within both public and private sectors. Additionally, structural efforts of social integration direct the processes for building inclusive and just institutions (Ferguson, 2008).

Openness to diversity implies that the attitudes of individuals and institutions are reflected through an overall evaluation of cultural and structural diversity (Phelps, Eilertsen, Türken, \& Ommundsen, 20II). Research shows that in the working environment, openness to diversity may influence effectiveness in interactions and collaborative decision-making. Also, improved openness to perceived differences may lead to improved outcomes in the newly established groups (Fujimoto, Härtel, \& Härtel, 2004). Generally, students' association with a higher education institution, meeting students from different backgrounds, and cooperative 
communication and learning has revealed positive effects on openness to diversity (Pacarella, Edison, Nora, Hagedorn, \& Terenzini, 1996).

\section{Domestic Aggression}

In the literature, it is not uncommon to find a certain level of confusion between the concepts of domestic aggression and domestic violence. Violence is viewed as a subdivision of the broader concept of aggression. Aggression is commonly defined as either impulsive or premeditated behavior deliberately planned to harm another individual who is motivated to avoid the harm (e.g., Bushman \& Huesmann, 2010). Aggressive behavior is included to the subdomain of violence-when a physical force is used with the purpose to cause physical harm or injury.

Several authors include also behaviors which are nonphysical in their definition of domestic violence; e.g. Davis (2008), who categorizes domestic violence into the following types: physical (e.g., hitting, slapping), sexual (e.g., attempting to obtain sexual favors by coercion), emotional (e.g., imposing negative emotions on a victim through manipulative behavior), economic (e.g., the abuser makes the victim financially reliant), or psychological (e.g., the abuser invokes a fear of physical harm. In the current study, only physical and sexual aggression will be regarded as violence, and other forms will be seen as forms of nonphysical aggression. Accordingly, the term domestic aggression will be used to cover all forms of aggression occurring in home settings. When the term domestic violence is used, it connotes particularly physical aggression, which occurs in the home.

Domestic aggression is a serious human rights and public health concern, and a social issue essentially affecting all societies. This type of aggression often goes unrecognized and unreported. Still today, in many countries, it is accepted as part of normal behavior (Krantz, 2002). It has been documented that victimization from domestic aggression can occur to anyone and anywhere despite the victim's socioeconomic background, race, age, gender, sexual orientation, or religion. It can vary in seriousness, chronicity, and frequency. Incidents of domestic aggression may occur among partners, family members, and children (Davis, 2008). 


\section{Domestic Aggression in the Finnish Context}

Domestic aggression occurs in even the most prosperous countries, and consequentially welfare societies may fail to distinguish domestic aggression (Husso et al., 2012). In Finland, as in many other countries, domestic aggression was, in previous times, politically viewed as a nonpublic issue that did not require intervention by the law enforcement, although it was recognized as a great societal problem. A significant public attention and research interest on this matter took place in the 1990s (Fagerlund, Houtsonen, Notko, \& Husso, 2020). A national policy against domestic aggression was then launched, in which violence in close relationships was separated from the criminal justice perspective. This improvement led to the recognition that all forms of assault in close relationships, including petty assaults, are subjected to punishable acts on a behalf of the state. A principle key factor for this development was the international pressure initiated by the $\mathrm{UN}$ and $\mathrm{EU}$, as well as by the transnational feminist movement. Despite the improvements, a proneness to underestimate domestic aggression as a public issue still prevails today (Ronkainen, 2008).

Intimate partner violence tends to be either increasing or at least reported more frequently in the country. In 2019, there were 10,600 registered offences of domestic violence and intimate partner violence, which is an increase of $7 \%$ in comparison with 2018 . Seventy-five percent of those victims were adults, and $25 \%$ were age minors. Half of the adult victims were in the age group between 25 and 44 , and $76.8 \%$ of the total number were women. Women tend to be suffering from intimate partner violence more than men; three out of four adult victims are women. They are mostly subjected to violence within the family contexts. Sexual violence is particularly common in the case of women and girls. In comparison, men encounter violence more often in public places, when the perpetrator is another man (Official Statistics of Finland, 2019).

Gender inequality is considered as one of the main reasons explaining violence against women. Hence, frequency and degree of domestic violence are expected to decrease as level of gender equality increases in a country. Yet, in Western nations, high levels of gender equality within the country are not necessarily connected to low occurrences of domestic aggression. The high levels of occurrences of intimate partner violence against women in countries with high 
levels of gender equality has been described as the "Nordic paradox" (Gracia, MartínFernández, Lila, Merlo, \& Ivert, 2019). However, it may be explained by a greater tendency to report about abuse in these countries.

\section{Domestic Aggression in Relation to Social Variables}

It is well established that domestic aggression is a great social and health concern, and largely a hidden crime. It has been explored from various viewpoints, namely interpersonal, intrapersonal, demographic, cultural, and feminist. Even though the root causes of this behavior remain unclear, such social factors as socio-demographics (e.g., age, socioeconomic status, ethnicity) and social integration (e.g., religious involvement, participation in social activities) are consistently associated with the phenomenon (Soler, Vinayak, \& Quadagno, 2000).

Domestic Aggression in Relation to Socio-Demographics

Aggression against women and girls is a predominant abuse of human rights promoting the risks of severe, and intergenerational long-lasting health effects (Yount, Krause, \& Miedema, 2017). Several studies bear witness about the frequency and negative effects of domestic aggression against women (e.g., Pallikadavath \& Bradley, 2019; Piispa, 2004; Wilt \& Olson, 1996) and adolescent girls (Nyato et al., 2019; Sterzing et al., 2020). A Finnish study of 22,398 women aged 19-54 showed that violent incidents in any type of close relationship during the 2018 was $7,6 \%$. Women who have been exposed to violence had significantly worse scores on quality of life and psychological distress in comparison to unexposed women. Tight connections were found between combinations of aggression and both quality of life and mental health measures (Hisasue, Kruse, Raitanen, Paavilainen, \& Rissanen, 2020). Furthermore, marginalized women run a statistically higher risk of victimization from domestic violence than other women. This group is characterized by divorced housewives with children who reside in rural areas, have less income, and lower educational level. Typical for this group are also women who have bad health, are older aged, immigrants, and those who have suffered some physical violence from other people previously (Martinex, 2019). 
Domestic aggression is relatively common among children and adolescents, and there is vast research-based documentation of it (Al-Krenawi, Graham, \& Sehwail, 2007; Lepistö, Luukkaala, \& Paavilainen, 20I I; Shaffer, Adjei, Viljoen, Douglas, \& Saewyc, 20I8). Among young people, the occurrences of violence are alarming, and thus there are leading gender differences in its exposure. For instance, in Sweden, a cross-sectional study of 2,250 women and 920 men aged 15-23 years found that emotional, physical, and sexual abuse is prevalent among both genders. However, young women informed about more damaging effects from all types of abuse. Thus, they were more frequently abused by a person who is close to them (Danielsson, Blom, Nilses, Heimer, \& Högberg, 2009). In another study with almost 4,000 young participants, it was found that there is a high rate of young people who are being involved in repeated violence. The probability of repeated violence occurrences increases remarkably with every new event (Boxall \& Morgan, 2020). Furthermore, a study by Jung et al. (2019) showed that physical and emotional child abuse and domestic violence exposure predict a higher likelihood of multitype aggression. A cycle of violence that is generationally transmitted within families tends to increase children's risk of both perpetration and victimization in adulthood. It is a well-recognized that children who experience violence often are also exposed to other stressful life situations. These early childhood circumstances give bases for a likelihood of victimization later in life as well (Jung et al., 2019).

Domestic aggression affects ethnic minorities disproportionately, and thus, cultural contexts are of importance in the assessments of rates of occurrences. Related to culture and minority status are considerations of family structure, immigration, acculturation, oppression, and community response (Kasturirangan, Krishnan, \& Riger, 2004). The association between domestic aggression and mental health related outcomes tends to be much stronger for minority populations (Gómez \& Freyd, 2018). Additionally, differences in socioeconomics and foreign-born rankings impact physical and mental health outcomes; presence of domestic aggression further aggravates health consequences (Forster, Grigsby, Soto, Sussman, \& Unger, 2017; Stockman, Hayashi, \& Campbell, 20I5). Overall, domestic aggression is more likely to occur among marginalized groups, including individuals of lower socioeconomic status in terms of education, income, and occupation (Khalifeh, Hargreaves, Howard, \& Birdthistle, 2013; Sampselle, Petersen, Murtland, \& Oakley, 1992). The influence of ethnicity in domestic 
aggression may be blurred in research because high proportions of victims belonging to ethnic minorities also have a low socioeconomic status (Lipsky \& Caetano, 2007).

\section{Domestic Aggression in Relation to Social Integration}

In cases of domestic aggression, social support plays an important role in reporting, seeking for help, and receiving support. There are two distinguished types of formal (a.k.a. institutional) and informal (a.k.a. social) support. Individuals may access formal support from doctors, police, or social services, for instance. Informal support refers to having access to available information and resources that contribute to help-seeking behavior (Berkman, Glass, Brissette, \& Seeman, 2000). Importantly, informal support is one of the main instruments through which social relationships influence health-related outcomes. This type of support can be accessed through contacts with relatives, friends, neighbors, and coworkers (Belknap, Melton, Denney, Fleury-Steiner, \& Sullivan, 2009). In addition to individual characteristics, behaviors, and risk factors, social context and environment may amplify (Merli, Moody, Mendelsohn, \& Gauthier, 20I5) or alleviate risks (Goldsmith \& Albrecht, 20II).

Isolation prevents the access to any kind of support. In women populations, higher income and better networks give access to a greater number and a larger variety of both formal and informal support (Bosch \& Schumm, 2004). In addition, young, educated, employed, married, and community-born women are likely to have a better access to both types of support (Gauthier, Francisco, Sara, Khan, \& Dombrowski, 2018). Disadvantaged women are less likely to receive any support at all, and if so, they seek formal support more often. It has been shown that women from minority backgrounds (Hollenshead, Dai, Ragsdale, Massey, \& Scott, 2006), with less income (Barrett \& St. Pierre, 20I I), with less education (Belknap, Melton, Denney, Fleury-Steiner, \& Sullivan, 2009), and who have been in abusive relationships longer (Anderson, Renner, \& Bloom, 20I4) trust informal support less.

Longitudinal studies have shown that the perpetration of domestic aggression is closely associated with individual, family, and peer factors, which develop during childhood (Linder \& Collins, 2005; Tharp et al., 2012). These emergencies and experiences exceed mere viewpoints to the perpetration and toleration of violence. It is dependent on the society in 
question and the social norms practiced within the specific social environment. Social norms affect the comprehension of child rearing practices and the perception of gender roles in a particular cultural setting. These social norms are imbedded in the attitudes of key people within the victim's social environment as well as in social and cultural institutions within the socioecological system. They are critical drivers to either the prevention or perpetuation of aggression (Lilleston, Goldmann, Verma, \& McCleary-Sills, 2017).

\section{Method}

Sample

A questionnaire was distributed in both online and paper-and-pencil versions using a convenience and snowball sampling procedure in Ostrobothnia in Western Finland. The questionnaire was distributed in educational and other institutions within the region. The questionnaire was completed by 298 Swedish speakers, of which 208 were females and 90 males. The mean age was 31.6 years $(S D=13.5)$. The age ranged was between 16 and 90 years. Level of education was also recorded, and those having passed the Finnish student matriculation test $(56.2 \%)$ were considered as having a higher education, while those who had not passed this test (43.8\%) were defined as having a lower education.

\section{Instrument}

Social integration was assessed with four subscales: Access to Social Benefits ( 8 items, $\alpha=$ .83), Satisfaction with the Neighborhood (8 items, $\alpha=.82$ ), Positive Social Relations (4 items, $\alpha=.72)$, and Trust in the Finnish Judiciary System $(7$ items, $9 \alpha=.80)$. The scales are presented in detail in Grigaitytè, Österman, Björkqvist (2020). Some sample items are presented in brackets in the following: Access to Social Benefits ("I can easily receive an education", "I can easily access public services such as hospitals, police, FPA (KELA) etc.”); Satisfaction with the Neighborhood (“I talk with my neighbors often”, “I know my neighbors well”); Positive Social Relations ("People from different groups perceive me in a positive way", "It is easy for me to communicate with people from different ethnic groups in different social settings"), and Trust in the Finnish Judiciary System ("I respect and obey Finnish laws", "I get the same benefits as 
everyone else in this country"). All response alternatives were on a five-point scale $(0=$ disagree completely, I = partly disagree, 2 = neutral, 3 = partly agree, 4 = agree completely).

Proactive attitudes towards the integration of immigrants were assessed with three subscales measuring Cultural Efforts required to facilitate the integration of immigrants (7 items, $\alpha=$ .82 ); Structural Efforts required for the same purpose (8 items, $\alpha=.86$ ); and Openness to Diversity (6 items, $\alpha=.89)$. The scales are based on an instrument developed by Phelps, Eilertsen, Türken, and Ommundsen (20I I), and specifically adapted and pilot tested for use in this study (see Grigaitytė, Österman, Björkqvist, 2019). The subscales are presented in detail, including all items, in Grigaitytė et al. (2019). Some sample items are presented in brackets in the following: Cultural Efforts ("Finnish people should not let their own culture be influenced by immigrants", "Finnish people should be more open and welcoming toward the customs of ethnic minorities"); Structural Efforts ("Immigrants cannot expect that public services are tailored for them", "Laws and rules should be adjusted so that it is easier for immigrants to feel integrated in society"); and Openness to Diversity ("People with other cultural backgrounds enrich the Finnish society", "It is a positive thing to have ethnic minority cultures in Finland”). Response alternatives were on a five-point scale ( $0=$ disagree completely, I = partly disagree, 2 = neutral, 3 = partly agree, 4 = agree completely).

Witnessing of domestic aggression was assessed with a scale particularly designed for use in this study. It was an abbreviated version of the Direct \& Indirect Aggression Scale for Adults (DIAS-Adult; Österman \& Björkqvist, 2009). It consisted of I I items measuring witnessing of domestic aggression, including physical, verbal, and indirect forms. Respondents were asked to choose an alternative on a five-point scale $(0=$ never, $\mathrm{I}=$ seldom, $2=$ sometimes, $3=$ often, 4 = very often) to respond to the question "Do any of the people in your household do the following things to each other?". For single items and Cronbach's alpha for the scale, see Table I. 
Table I

Items of the Scale Measuring Witnessing of Domestic Aggression $(N=298)(\alpha=.93)$

I. Shout and scream

2. Call someone bad names

3. Say insulting things

4. Talk badly about another behind his/her back

5. Threaten someone

6. Slap someone

7. Hit someone with the hand

8. Hit someone with an object

9. Throw things

10. Break things

II. Force someone else to do things he/she doesn't like

\section{Ethical Considerations}

The study was conducted in accordance with human research ethics of the Declaration of Helsinki (World Medical Association, 2013) and it followed the Finnish Advisory Board on Research Integrity guidelines (2012). The main principles applied in the project were honesty with the participants about the purpose of the research, participants' informed consent before the questionnaire was filled in, voluntary participation, avoiding harm of participants, proper handling, and publication of data, and emphasized confidentiality. All participants were adults and the topic of research had involved minimum risks to the participants. The research material is safely stored. The handling and publication of data adhered to the regulations of data protection issued by European Commission (2016).

\section{Results}

Witnessing of Domestic Aggression

The scores on the scale measuring witnessing of domestic aggression were overall low in the sample. The mean score on the scale was 0.31 ( $S D=0.53)$, with the maximum score being 4 . (There were, however, single cases receiving the full maximum score, indicating that the respondent had marked the maximum score on every single item of the scale.) The mean 
score for "slapping" was 0.12 , for "hitting with the hand" 0.11 , and for "hitting with an object" 0.II. These figures show that witnessing of physical violence was extremely rare in this sample.

\section{Sex Differences}

There was a significant sex differences in the experience of witnessing domestic aggression within the sample. Male respondents reported that they had witnessed domestic aggression more often than female respondents. The mean score for males was $0.48(S D=0.76)$ and for females $0.24(\mathrm{SD}=0.37)[\mathrm{t}(20 \mathrm{I})=3.02, \mathrm{p}=.003]$.

Sex differences in the four scales measuring social integration (Access to Social Benefits, Satisfaction with the Neighborhood, Positive Social Relations, and Trust in the Finnish Judiciary System) have been reported elsewhere (Grigaitytè et al., 2020) and will accordingly not be reported here. Sex differences in the three scales measuring proactive attitudes towards the integration of immigrants (Cultural Efforts, Structural Efforts, and Openness to Diversity) have likewise been reported elsewhere (Grigaitytè et al., 2019).

Witnessing Domestic Aggression in Relation to Social Integration and Proactive Attitudes towards the Integration of Immigrants

The sample was divided into two groups based on their scores on the scale of Witnessing of Domestic Aggression. After standardizing the scores into z-scores, all participants having a score $\geq 0$ on the scale were defined as belonging to the high scoring group, and those with scores $<0$ belonged to the low scoring group.

A multivariate analysis of variance (MANOVA) was conducted with scores on Witnessing of Domestic Aggression (High vs. Low) serving as the independent variable, and scores on the four scales measuring social integration and scores on the three scales measuring proactive attitudes towards the integration of immigrants serving as dependent variables. The findings are presented in Table 2 and Figure I. 
Table 2

Results of a Multivariate Analysis of Variance (MANOVA) with Witnessing of Domestic Aggression (High/Low) as Independent Variable and Seven Scales Measuring Aspects of Social Integration and Proactive Attitudes towards Integration of Immigrants as Dependent Variables $(\mathrm{N}=298)$. Cf. Fig. I.

\begin{tabular}{lllll}
\hline & $\mathrm{F}$ & $\mathrm{df}$ & $\mathrm{P} \leq$ & $\mathrm{nP} 2$ \\
\hline Multivariate Analysis & 4.19 & 7,195 & .001 & .131 \\
Univariate Analyses & & & & \\
Access to Social Benefits & 11.42 & $\mathrm{I}, 20 \mathrm{I}$ & $.00 \mathrm{I}$ & .054 \\
Satisfaction with the Neighborhood & 2.36 & “ & n.s. & .012 \\
Positive Social Relations & 11.36 & “ & .001 & .053 \\
Trust in the Finnish Judiciary System & 9.47 & “ & .002 & .045 \\
Cultural Efforts & 19.14 & “ & .001 & .087 \\
Structural Efforts & 6.45 & “ & .012 & .031 \\
Openness to Diversity & 14.13 & “ & .001 & .066 \\
\hline
\end{tabular}

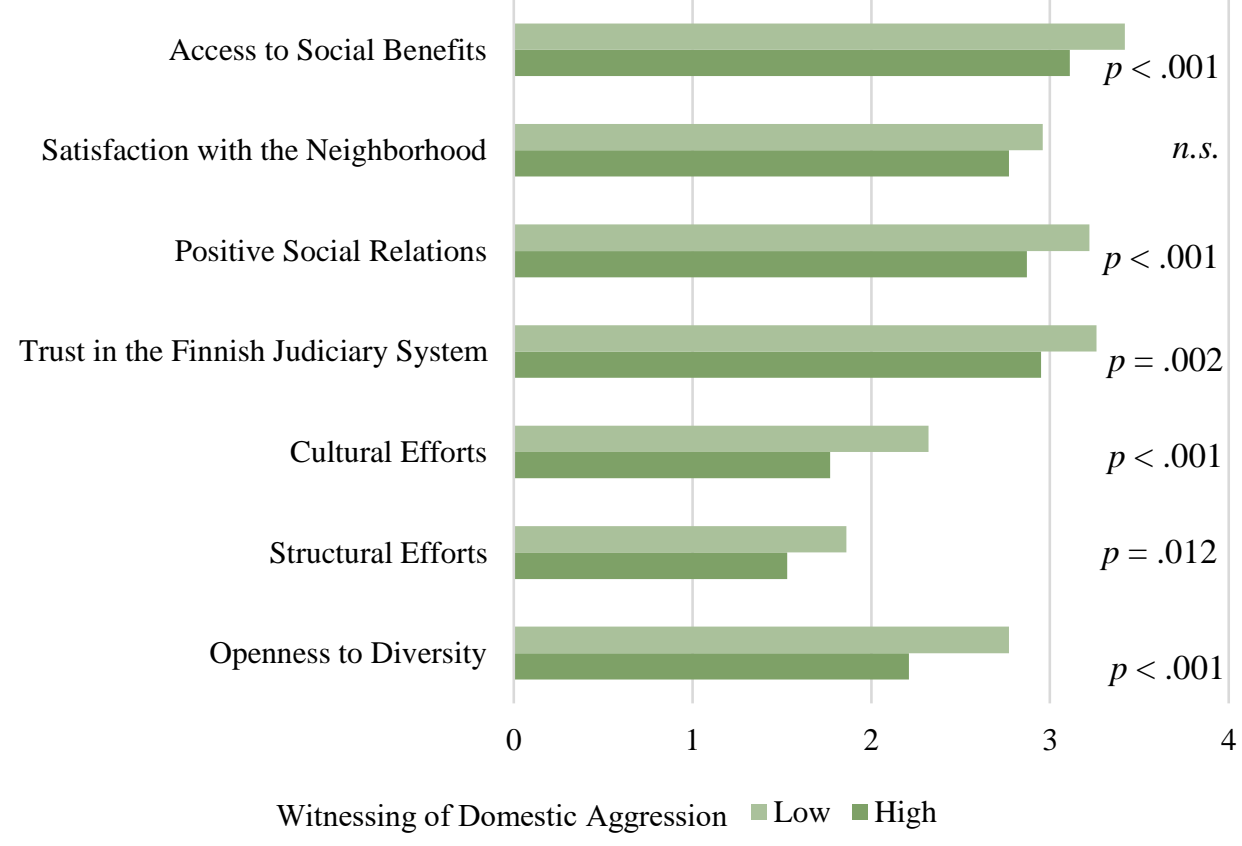

Fig. I. Mean values for respondents belonging to the High and Low groups on Witnessing of Domestic Aggression on the dependent variables $(N=298)$. Cf. Table 2. 
As Table 2 and Figure I reveals, the low scoring group on Witnessing of Domestic Aggression scored significantly higher on all dependent variables except one (Satisfaction with the Neighborhood).

\section{Witnessing Domestic Aggression and Level of Education}

There was a significant association between Witnessing of Domestic Aggression and a level of education: those who had a lower level of education (= had not passed the Finnish student matriculation test) were over-represented in the high scoring group on Witnessing of Domestic Aggression $\left[\chi_{(1)}^{2}=4.98, p=.026\right)$.

\section{Discussion}

Previous research suggests connections between factors such as socio-demographics, social integration, and domestic aggression (Soler, Vinayak, \& Quadagno, 2000). In the current study, the association between witnessing domestic aggression and levels of social integration as well as attitudes towards the integration of immigrants in a sample of the Swedish-speaking minority of Western Finland were explicitly assessed. As expected, an association between the studied factors was found, indicating that there is a connection between the social background of individuals in terms of witnessing and experiencing domestic aggression.

First, the data shows that the scores on the scale measuring witnessing of domestic aggression were overall low within the study population. Previous research suggests that domestic aggression affects ethnic minorities disproportionately, and therefore, cultural contexts are important when assessing the rates of domestic aggression occurrences (Kasturirangan, Krishnan, \& Riger, 2004). The Swedish-speaking population of Finland is viewed as a relatively well-integrated minority. Their culture and language are secured by the national constitution and other relevant legislation. Thus, this minority has for over 800 -years been actively preserving its own culture through education, employment, media, religion, and politics (Engman, 1995; Saarela, 2020; Tarkiainen, 2008; Törnblom, 1993). A strong sense of social integration deriving from formal and informal social support may contribute to the low levels of domestic aggression, even though domestic violence tends to either be increasing or at 
least be reported more frequently in the country. Thus, previous research suggests that perpetration of domestic aggression is closely linked to social environment, including cultural norms, values, and attitudes that consequentially determine how a particular culture view aggression and violence (Lilleston, Goldmann, Verma, \& McCleary-Sills, 2017; Linder \& Collins, 2005; Tharp et al., 2012). Reasonably, in a case of the studied population, their cultural and social norms expressed in formal and informal relationships contribute to low levels of aggression.

Second, respondents who reported higher than average scores on witnessing of domestic aggression reported lower scores than others on the scales of access to social benefits, positive social relations, and trust in the Finnish judiciary system that measured social integration. There was, however, one exception for the scale that measured satisfaction with the neighborhood. Primarily, these results support the initial hypothesis that individuals who are well-integrated in their society witness less domestic aggression. Studies show that individuals who have resources to access social services (e.g., health care, education), perceive their social relationships with family, friends, and immediate acquaintances positively, and have confidence and trust in the institutions, witness less of domestic aggression. Additionally, having a strong sense of social integration positively influences health-related outcomes, including physical and psychological health (e.g., Belknap, Melton, Denney, Fleury-Steiner, \& Sullivan, 2009; Berkman, Glass, Brissette, \& Seeman, 2000; Bosch \& Schumm, 2004).

Third, respondents who scored higher than average on witnessing domestic aggression scored also lower than others on proactive attitudes towards the integration of immigrants. Proactive attitudes towards integration include cultural efforts, structural efforts, and openness to diversity, enveloping potential efforts, willingness, and responsibilities by both individuals and the state during the integration processes of immigrants (Phelps, Eilertsen, Türken, \& Ommundsen, 20I I). The current data shed light on the relation between domestic aggression and proactive attitudes towards others in the study population. Evidently, individuals living within the social and cultural contexts where interpersonal aggression is more common, also fall into a group whose attitudes towards integration of immigrants are more negative. It is likely that individuals who witness higher levels of domestic aggression are more fearful and 
have a higher sense of inequality and injustice, which in turn may hinder them from being open towards the immigrants and immigration.

Fourth, in terms of gender differences, men reported the witnessing of domestic aggression more often than women. This result challenges existing research and literature where several studies demonstrate a higher frequency of domestic aggression against women and girls (Nyato et al., 2019; Pallikadavath \& Bradley, 2019; Piispa, 2004; Sterzing et al., 2020; Sterzing et al., 2020Wilt \& Olson, 1996). Consequently, in Finland, women report and suffer from domestic aggression (Hisasue, Kruse, Raitanen, Paavilainen, \& Rissanen, 2020) and intimate partner violence more than men; three out of four adult victims of domestic violence are women (Official Statistics of Finland, 2019). In Sweden, it was found that emotional, physical, and sexual abuse are prevalent among both genders; nevertheless, women report more severe adverse effects from all types of abuse (Danielsson, Blom, Nilses, Heimer, \& Högberg, 2009). In this study, the domestic aggression scale included physical, verbal, and indirect forms of violence. Women tend to employ more verbal and indirect forms of aggression, which may be a plausible explanation to this exception. Thus, men in this population may be moving from social stigma as well as they might be receiving political and institutional support, which in turn challenges the results of the mainstream reports. Also, domestic aggression against men is becoming more recognized by the society in general. Additionally, women of this study population may have a strong socioeconomic status, which in turn may decrease their witnessing and experiencing domestic aggression.

Finally, this study found a strong association between witnessing domestic aggression and level of education. More particularly, respondents who had a lower level of education witnessed more of domestic aggression. This result corresponds with the results of previous studies showing that individuals with low education experience and witness more of domestic aggression (Khalifeh, Hargreaves, Howard, \& Birdthistle, 2013; Sampselle, Petersen, Murtland, \& Oakley, 1992) and statistically have higher risk of victimization from domestic violence (Martinex, 2019) in combination with other socio-demographic factors. 


\section{Conclusion}

The study sheds light on the current situation of the Swedish-speaking minority of Western Finland in terms of their level of social integration and their attitudes towards the integration of immigrants in relation to witnessing domestic aggression. The studied aspects clearly have an association with one another. Still, there is much to be learned about the pathways in which formal and informal relationships and socio-cultural attitudes towards others influence domestic aggression, which provides bases for future research among various populations worldwide.

The current study provides a characteristic profile of individuals who experience more of domestic aggression. Specifically, these are individuals who live in the families where interpersonal aggression is more common, individuals who are poorly integrated in their social environment, and individuals who have more negative attitudes towards the integration of immigrants. Clearly, there is an impact of social relationships affecting and influencing physical, psychological, and emotional health of individuals. This knowledge may be taken into consideration by the policy makers who might work on improving health of individuals and societies by promoting and protecting social relationships.

\section{Acknowledgment}

The first author acknowledges the support from Kone Foundation [Koneen säätiö] for financial doctoral thesis contributions.

\section{References}

Al-Krenawi, A., Graham, J. R., \& Sehwail, M. A. (2007). Tomorrow's players under occupation: An analysis of the association of political violence with psychological functioning and domestic violence, among Palestinian youth. American Journal of Orthopsychiatry, 77, 427-433.

Ager, A., \& Strang, A. (2008). Understanding integration: A conceptual framework. Journal of Refugee Studies, 21 , 166-191.

Anderson, K. M., Renner, L. M., Bloom, T. S. (20I4). Rural women's strategic responses to intimate partner violence. Health Care for Women International, 35, 423-44I.

Barrett, B. J., St. Pierre, M. (20I I). Variations in women's help seeking in response to intimate partner violence: Findings from a Canadian population-based study. Violence Against Women, 17, 47-70. 
Belknap, J., Melton, H. C., Denney, J. T., Fleury-Steiner, R. E., \& Sullivan, C. M. (2009). The levels and roles of social and institutional support reported by survivors of intimate partner abuse. Feminist Criminology, 4, 377-402.

Berkman, L. F., Glass, T., Brissette, I., \& Seeman, T. E. (2000). From social integration to health: Durkheim in the new millennium. Social Science \& Medicine, 5I, 843-857.

Brissette, I., Cohen, S., \& Seeman, T. E. (2000). Measuring social integration and social networks. In S. Cohen, L. G. Underwood, \& B. H. Gottlieb (Eds.), Social support measurement and intervention: A guide for health and social scientists (pp. 53-85). Oxford, UK: Oxford University.

Boxall, H. \& Morgan, A. (2020). Repeat domestic and family violence among young people. Trends and Issues in Crime and Criminal Justice, 59l, I-I7.

Bushman, B. J., \& Huesmann, L. R. (20I0). Aggression. In S. T. Fiske, D. T. Gilbert, \& G. Lindzey (Eds.), Handbook of social psychology, 5th ed. (pp. 833-863). New York: John Wiley.

Cohen, S. (2004). Social relationships and health. American Psychologist, 59, 676684. doi:0.1037/0003-066X.59.8.676

Danielsson, I., Blom, H., Nilses, C., Heimer, G., \& Högberg, U. (2009). Gendered patterns of high violence exposure among Swedish youth. Acta Obstetricia et Gynecologica Scandinavica, 88, 528-535.

Davis, R. L. (2008). Domestic violence: Intervention, prevention, policies, and solutions. Boca Raton, Florida, US: Routledge \& CRC Press.

Engman, M. (1995). Finns and Swedes in Finland. In S. Tägil (Ed.), Ethnicity and nation building in the Nordic world (pp. 179-216). London, UK: Hurst.

European Commission (2016). Data protection. Rules for the protection of personal data inside and outside the EU. https://ec.europa.eu/info/law/law-topic/data-protection_en

Esser, H. (1980). Aspekte der Wanderungssoziologie. Assimilation und Integration von Wanderern, ethnischen Gruppen und Minderheiten. Darmstadt, Germany: Luchterhand.

Fagerlund, M., Houtsonen, J., Notko, M., \& Husso, M. (2020). Conceptualising violence in close relationships: Discrepancies between police conceptions and the letter of the law in Finland. European Journal on Criminal Policy and Research, 6, I-20.

Ferguson, C. (2008). Promoting social integration (Report commissioned by the United Nations Department of Economic and Social Affairs (UNDESA) for the Expert Group Meeting on Promoting Social Integration). http://www.gsdrc.org/docs/open/se6.pdf

Finnish Advisory Board on Research Integrity. (2012). Responsible conduct of research and procedures for handling allegations of misconduct in Finland. Helsinki, Finland: Finnish Advisory Board on Research Integrity.

Fujimoto, Y., Härtel, C. E. J., \& Härtel, G. F. (2004). A field test of the diversity-openness moderator model in newly formed groups: Openness to diversity affects group decision effectiveness and interaction patterns. Cross cultural Management: An -International Journal, II, 4-16.

Saarela, J. (2020). Den svenskspråkiga befolkningens utveckling i Finland 1990-2040. Helsinki, Finland: Nord Print.

Forster, M., Grigsby, T. J., Soto, D. W., Sussman, S. Y., \& Unger, J. B. (20I7). Perceived discrimination, cultural identity development, and intimate partner violence among a sample of Hispanic young adults. Cultural Diversity and Ethnic Minority Psychology, 23, 576583. 
Gauthier, G. R., Francisco, Sara C., Khan, B., \& Dombrowski, K. (2018). Social integration and domestic violence support in an indigenous community: Women's recommendations of formal versus informal sources of support. Journal of Interpersonal Violence, 33, 1679_ 1699.

Gracia, E., Martín-Fernández, M., Lila, M., Merlo, J., \& Ivert, A. K. (2019). Prevalence of intimate partner violence against women in Sweden and Spain: A psychometric study of the 'Nordic paradox'. PloS One, 14, e02I70I5.

Grigaitytè, I., Österman, K., \& Björkqvist, K. (2019). Proactive attitudes towards integration and intense group identification, in a sample of the Swedish-speaking minority of Western Finland. European Journal of Social Science, Education and Research, 6(3), 23-36.

Grigaitytè, I., Österman, K., \& Björkqvist, K. (2020). Social integration and psychological wellbeing in a sample of the Swedish-speaking minority of western Finland. Technium Social Science Journal, 9, 364-376.

Goldsmith, D. J., \& Albrecht, T. L. (20I I). Social support, social networks, and health. In T. L. Thompson, R. Parrott, \& J. F. Nussbaum (Eds.), The Routledge handbook of health communication (pp. 335-348). New York: Routledge.

Gómez, J. M., \& Freyd, J. J. (2018). Psychological outcomes of within-group sexual violence: Evidence of cultural betrayal. Journal of Immigrant and Minority Health, 20, I458-I467.

Hisasue, T., Kruse, M., Raitanen, J., Paavilainen, E., \& Rissanen, P. (2020). Quality of life, psychological distress and violence among women in close relationships: a populationbased study in Finland. BMC Women's Health, 20, I-10.

Hollenshead, J. H., Dai, Y., Ragsdale, M. K., Massey, E., Scott, R. (2006). Relationship between two types of help seeking behavior in domestic violence victims. Journal of Family Violence, 2 I, 27I-279.

Husso, M., Virkki, T., Notko, M., Holma, J., Laitila, A., \& Mäntysaari, M. (20I2). Making sense of domestic violence intervention in professional health care. Health \& Social Care in the Community, 20, 347-355.

Jung, H., Herrenkohl, T. I., Skinner, M. L., Lee, J. O., Klika, J. B., \& Rousson, A. N. (2019). Gender differences in intimate partner violence: A predictive analysis of IPV by child abuse and domestic violence exposure during early childhood. Violence against Women, 25, 903-924.

Kasturirangan, A., Krishnan, S., \& Riger, S. (2004). The impact of culture and minority status on women's experience of domestic violence. Trauma, Violence, \& Abuse, 5, 318-332.

Khalifeh, H., Hargreaves, J., Howard, L. M., \& Birdthistle, I. (20I3). Intimate partner violence and socioeconomic deprivation in England: findings from a national cross-sectional survey. American Journal of Public Health, 103, 462-472.

Krantz, G. (2002). Violence against women: a global public health issue!journal of Epidemiology \& Community Health, 56, 242-243.

Kuran, T., \& Sandholm, W. H. (2008). Cultural integration and its discontents. The Review of Economic Studies, 75, 20I-228.

Lilleston, P. S., Goldmann, L., Verma, R. K., \& McCleary-Sills, J. (20I7). Understanding social norms and violence in childhood: Theoretical underpinnings and strategies for intervention. Psychology, Health \& Medicine, 22, 122-134.

Lepistö, S., Luukkaala, T., \& Paavilainen, E. (20II). Witnessing and experiencing domestic violence: A descriptive study of adolescents. Scandinavian Journal of Caring Sciences, 25, 70-80. 
Linder, J. R., \& Collins, W. A. (2005). Parent and peer predictors of physical aggression and conflict management in romantic relationships in early adulthood. Journal of Family Violence, 19, 252-262.

Lipsky, S., \& Caetano, R. (2007). The role of race/ethnicity in the relationship between emergency department use and intimate partner violence: Findings from the 2002 National Survey on Drug Use and Health. American Journal of Public Health, 97, 22462252.

Martinez, P. R. (2019). Intimate partner violence against women in Scandinavia and Southern Europe. Comparative Sociology, 18, 265-289.

Merli, M. G., Moody, J., Mendelsohn, J., \& Gauthier, R. (20I5). Sexual mixing in Shanghai: Are heterosexual contact patterns compatible with an HIVIAIDS epidemic? Demography, 52, 919-942.

Nyato, D., Materu, J., Kuringe, E., Zoungrana, J., Mjungu, D., Lemwayi, R., ... \& Komba, A. (2019). Prevalence and correlates of partner violence among adolescent girls and young women: Evidence from baseline data of a cluster randomised trial in Tanzania. PLoS One, 14, e0222950.

Official statistics of Finland. (202I, May I I). Population. https://www.stat.fi/tup/suoluk/suoluk_vaesto_en.html\#Population\%20by\%20origin\%20and \%20language,\%202019

Official statistics of Finland. (2019, June 6). Statistics on offences and coercive measures. http://www.stat.fi/til/rpk/20I8/I5/rpk_20I8_I5_2019-06-06_tie_00I_en.html

Österman, K., \& Björkqvist, K. (2009). DIAS-Ā⿲ult. Vasa, Finland: Åb̄o Akademi University.

Pallikadavath, S., \& Bradley, T. (2019). Dowry,'dowry autonomy'and domestic violence among young married women in India. Journal of Biosocial Science, 5I, 353-373.

Pascarella, E. T., Edison, M., Nora, A., Hagedorn, L. S., \& Terenzini, P. T. (I996). Influences on students' openness to diversity and challenge in the first year of college. Journal of Higher Education, 67, 174-195.

Phelps, J. M., Eilertsen, D. E., Türken, S., \& Ommundsen, R. (20I I). Integrating immigrant minorities: Developing a scale to measure majority members' attitudes toward their own proactive efforts. Scandinavian Journal of Psychology, 52, 404-4I0.

Piispa, M. (2004). Age and meanings of violence: Women's experiences of partner violence in Finland. Journal of Interpersonal Violence, 19, 30-48.

Ronkainen S. (2008) Kenen ongelma väkivalta on? Suomalainen hyvinvointivaltio ja väkivallan toimijuus. Janus, 73, 388-40I.

Tarkiainen, K. (2008). Sveriges Österland: Från forntiden till Gustav Vasa. Finlands svenska historia (vol. I). Helsingfors \& Stockholm: Svenska litteratursällskapet i Finland.

Tharp A. T, Degue S, Valle L. A., Brookmeyer K. A., Massetti G. M., Matjasko J. L. (2012). A systematic qualitative review of risk and protective factors for sexual violence perpetration. Trauma, Violence, \& Abuse, 14,133-167.

Törnblom, L. (1993). Medeltiden. In M. Norrback (Ed.), Finlands historia, I (pp. 27I-426). Espoo, Finland: Schildts.

Sampselle, C. M., Petersen, B. A., Murtland, T. L., \& Oakley, D. J. (1992). Prevalence of abuse among pregnant women choosing certified nurse-midwife or physician providers. Journal of Nurse-Midwifery, 37, 269-273.

Shaffer, C. S., Adjei, J., Viljoen, J. L., Douglas, K. S., \& Saewyc, E. M. (20I8). Ten-year trends in physical dating violence victimization among adolescent boys and girls in British Columbia, Canada. Journal of Interpersonal Violence, doi: I0.1 I 77/08862605 I8788367 
Strang, A., \& Ager, A. (2010). Refugee integration: Emerging trends and remaining agendas. Journal of Refugee Studies, 23, 589-607.

Sterzing, P. R., Auslander, W. F., Ratliff, G. A., Gerke, D. R., Edmond, T., \& Jonson-Reid, M. (2020). Exploring bullying perpetration and victimization among adolescent girls in the child welfare system: Bully-only, victim-only, bully-victim, and noninvolved roles. Journal of Interpersonal Violence, 35, I3 II-I333.

Stockman, J. K., Hayashi, H., \& Campbell, J. C. (20I5). Intimate partner violence and its health impact on ethnic minority women. Journal of Women's Health, 24, 62-79.

Soler, H., Vinayak, P. \& Quadagno, D. (2000). Biosocial aspects of domestic violence. Psychoneuroendocrinology, 25, 72I-739.

Uchino, B. N., Holt-Lunstad, J., Uno, D., Campo, R., \& Reblin, M. (2007). The social neuroscience of relationships. An examination of health-relevant pathways. In $E$. $\mathrm{H}$. Jones \& P. Winkielman (Eds.), Social neuroscience: Integrating biological and psychological explanations of social behavior (pp. 474-487). New York: The Guildford Press.

Umberson, D., \& Montez, J. K. (2010). Social relationships and health: a flashpoint for health policy. Journal of Health and Social Behavior, 5I(I_suppl), S54-S66.

Wilt, S., \& Olson, S. (1996). Prevalence of domestic violence in the United States. Jamwa, 5 I, 77-82.

World Medical Association (2013). Declaration of Helsinki: Ethical principles for medical research involving human subjects. JAMA, 310, 2191-2194.

World Health Association (20I0). Health of migrants - the way forward (Report of a global consultation). https://publications.iom.int/system/files/pdf/consultation_report_health_migrants.pdf

Yount, K. M., Krause, K. H., \& Miedema, S. S. (20I7). Preventing gender-based violence victimization in adolescent girls in lower-income countries: Systematic review of reviews. Social Science \& Medicine, 192, I-13. 